Regards sur l'économie allemande

Bulletin économique du CIRAC

105 | 2012

Varia

\title{
Karlsruhe : arrêts à propos du MES et autres
}

\section{Isabelle Bourgeois}

\section{OpenEdition \\ Journals}

Édition électronique

URL : http://journals.openedition.org/rea/4424

DOI : $10.4000 /$ rea.4424

ISBN : 978-2-8218-1420-2

ISSN : 1965-0787

Éditeur

CIRAC

Édition imprimée

Date de publication : 11 juillet 2012

Pagination : 37-38

ISSN : 1156-8992

Référence électronique

Isabelle Bourgeois, "Karlsruhe : arrêts à propos du MES et autres », Regards sur l'économie allemande [En ligne], 105 I juillet 2012, mis en ligne le 19 juillet 2012, consulté le 15 septembre 2020. URL : http:// journals.openedition.org/rea/4424

Ce document a été généré automatiquement le 15 septembre 2020.

(C) CIRAC 


\title{
Karlsruhe : arrêts à propos du MES et autres
}

\author{
Isabelle Bourgeois
}

1 Le 19 juin 2012, le Tribunal constitutionnel fédéral a rendu un important jugement dans lequel il précise l'obligation constitutionnelle faite au gouvernement fédéral d'associer le Bundestag dans la prise de décision sur tout traité relatif à l'UE et son fonctionnement (2 BvE 4/11). Cet arrêt s'inscrit dans la continuité de la jurisprudence de Karlsruhe à propos de l'intégration européenne : arrêt du 12 décembre 1993 sur les lois d'approbation du Traité de Maastricht (2 BvR 2134/92, 2 BvR 2159/92-BVerfGE 89, 155), décision du 31 mars 1998 sur l'introduction de l'Euro (BvR 1877/94, BVerfGE 97, 350) arrêt du 30 juin 2009 sur la loi d'approbation du Traité de Lisbonne (BvE 2/08 et al., BVerfGE 123, 267 ; voir REA 92/2009) et arrêt du 7 septembre 2011 sur la conformité avec la Loi fondamentale des lois allemandes sur l'aide budgétaire au sein de la zone Euro votées en mai 2010 (2 BvR 987/10, 2 BvR 1485/10, 2 BvR 1099/10).

\section{Le droit à information du Bundestag...}

2 Dans l'arrêt du 19 juin, la Cour définit plus précisément les droits du Bundestag tels qu'ils sont inscrits à l'art. 23 de la Loi fondamentale, qui autorise l'Allemagne à transférer des droits de souveraineté à l'UE. Elle prolonge de la sorte sont arrêt du 7 septembre 2011 qui rappelait le principe de démocratie et les obligations qui en découlent pour l'exécutif vis-à-vis du législatif (voir REA 102/2011). L'art. 23, § 2, 2 stipule en effet: "Le gouvernement fédéral doit informer le Bundestag et le Bundesrat de manière complète et aussi tôt que possible ". La Cour estime que, lors de la procédure de vote parlementaire relative au Mécanisme européen de stabilité (MES) et au Pacte pour l'Euro-Plus, le gouvernement fédéral a violé ce droit à information du Bundestag. 


\section{... implique une information " exhaustive et précoce »...}

3 En effet, le gouvernement avait omis de soumettre à temps aux députés le texte de la Commission européenne sur l'institution d'un MES (il en disposait dès le 21 février 2011), de même que le projet de Traité afférent, en date du 6 avril 2011. Certes, il les avait informés oralement et par écrit les 17 et 18 mai 2011 sur l'état d'avancement des négociations sur le MES, mais la transmission tardive de ce "paquet ficelé» ne leur avait pas laissé la latitude d'un examen approfondi. La violation de leur droit à information est d'autant plus grave dans le cas du Pacte pour l'Euro-Plus que celui-ci soumet au contrôle des organes de l'UE (certes sur une base volontaire, mais cela ne change rien quant au principe) des compétences législatives relevant de la souveraineté des parlements nationaux. Une "information exhaustive et précoce" est dès lors a fortiori impérative, puisqu'un tel contrôle implique une limitation sensible de la latitude de décision du parlement. Or dans ce cas aussi, le gouvernement fédéral avait tardé à informer le Bundestag sur son projet de Pacte pour la compétitivité (précurseur du Pacte pour l'Euro-Plus) présenté conjointement avec la France au Conseil européen du 4 février 2011, et omis de lui communiquer un document interne du président de la Commission et du Conseil en date du 25 février 2011 qui développait ce projet. Il n'avait transmis au Bundestag que le projet officiel, et ce le 11 mars 2011 seulement - soit le jour même de son adoption par les chefs d'Etat et de gouvernement.

\section{... surtout si les décisions limitent son pouvoir}

4 Désormais, donc, et même dans des procédures longues et complexes de prises de décision collectives, le gouvernement doit tenir informé le parlement par écrit et en temps réel afin de lui laisser le temps de se livrer à un examen approfondi du dossier et de prendre position avant que le gouvernement fédéral ne déclare publiquement l'engagement de l'Allemagne. Cette information «doit être d'autant plus exhaustive et suivie que le processus est complexe et qu'il empiète sur le domaine de compétences du législatif». Cet impératif ne souffre qu'une seule exception : " tant que le processus de prise de décision interne du gouvernement fédéral n'est pas achevé, le droit à information du parlement ne s'applique pas ».

\section{Saisine en référé le 29 juin...}

5 La Cour avait été saisie dans cette affaire par la Commission parlementaire de Bündnis 90/Die Grünen. Elle vient d'être à nouveau saisie - en référé, ce qui est rarissime - au lendemain du vote par le Bundestag et le Bundesrat, le 29 juin 2012, de plusieurs lois d'application relatives notamment au Traité instituant le MES, au Traité sur la stabilité, la coordination et la gouvernance au sein de l'UEM (TSCG ; voir dans ce numéro) et à la décision du Conseil européen du 25 mars 2011 sur la modification de l'art. 136 du Traité sur le fonctionnement de l'UE (TFUE) visant à renforcer les mécanismes de stabilité interne à la zone Euro. Les plaignants sont multiples, dont une association de citoyens pour «Plus de démocratie » (Mehr Demokratie e.V.), la commission parlementaire de DIE LINKE, et divers députés. Le point commun à toutes ces saisines est l'appréciation de "linterdiction de se dessaisir de la responsabilité budgétaire», faite au parlement (précisée dans l'arrêt du 7 septembre 2011), ainsi que la question de savoir dans quelle 
mesure la limitation de son autonomie budgétaire viole le droit de vote du citoyen. Cette saisine s'inscrit elle aussi dans la continuité de la jurisprudence du Tribunal constitutionnel fédéral et tout particulièrement des considérations développées dans l'arrêt du 7 septembre 2011 sur le pouvoir démocratique. La Cour y avait rappelé que "le droit du citoyen à la démocratie... se trouverait invalidé si le parlement abandonnait des éléments essentiels de l'autodétermination politique et retirait ainsi durablement au peuple son pourvoir d'influence démocratique ».

\section{... et délibéré attendu le 10 juillet}

Le délibéré de la Cour est fixé au 10 juillet 2012. En attendant, dès le lendemain de l'adoption des lois incriminées, elle avait demandé «à titre préventif» au président de la République de ne pas valider par sa signature les textes litigieux afin de disposer du temps nécessaire à l'examen des recours en référé déposés ou annoncés. (IB)

INDEX

Mots-clés : Tribunal Constitutionnel Fédéral, UE, Europe, Union européenne, politique européenne, Bundestag, pouvoir politique, droit, gouvernement 